Check for updates

Cite this: RSC Adv., 2018, 8, 8990

\title{
Lithium fluoride recovery from cathode material of spent lithium-ion battery
}

\author{
Ying Zheng, $\uparrow^{\mathrm{ab}}$ Wei Song, $\dagger^{\mathrm{b}}$ Wen-ting Mo, ${ }^{\mathrm{a}}$ Lai Zhou ${ }^{\mathrm{b}}$ and Jian-Wen Liu (D) *b
}

Recoveries of cobalt and lithium metals from spent lithium-ion batteries are very important for prevention of environmental pollution and alleviation of resource shortage. In this study, a hydrometallurgical route for the recovery of lithium fluoride was proposed. Lithium and cobalt could be first selectively leached into solution using formic acid and hydrogen peroxide. By investigating the effects of leaching temperature, time, stoichiometric ratio, $\mathrm{H}_{2} \mathrm{O}_{2}$ concentration and solid-to-liquid ratio, the leaching efficiency of $\mathrm{Li}$ and Co could reach $99.90 \%$ and $99.96 \%$, respectively. Meanwhile, the evaluation of leaching kinetics and calculation of apparent activation energies revealed that the leaching process fitted chemical control satisfactorily. After further fractional precipitation, a high purity of $99.0 \%$ lithium fluoride could be finally obtained, thus achieving the effective recovery of spent material from the lithium-ion battery.

Received 3rd January 2018

Accepted 13th February 2018

DOI: 10.1039/c8ra00061a

rsc.li/rsc-advances development because of the low cost, variety of leaching liquids and increasing efficiency of leaching.

According to the literature, the leaching liquids in hydrometallurgical processes can be classified as mineral acids, alkalis and organic acids. It has been reported that valuable metals such as cobalt and lithium can be leached out from spent LIBs using mineral acids such as $\mathrm{H}_{2} \mathrm{SO}_{4}, \mathrm{H}_{3} \mathrm{PO}_{4}$, and $\mathrm{HCl}$ and various organic acids such as succinic acid, ascorbic acid, and citric acid in the presence of reducing agents such as hydrogen peroxide $\left(\mathrm{H}_{2} \mathrm{O}_{2}\right)$. $^{4-7,9,11,12,14}$ Table 1 briefly summarizes the different leaching liquids used for recycling valuable metals from spent LIBs in the last 5 years. Chen et al. published a leading paper where they have reported using dimethylglyoxime reagent to recover nickel selectively, ammonium oxalate solution to precipitate cobalt as $\mathrm{CoC}_{2} \mathrm{O}_{4} \cdot \mathrm{H}_{2} \mathrm{O}$ and saturated sodium carbonate solution to precipitate lithium as $\mathrm{Li}_{2} \mathrm{CO}_{3}$ under optimized experimental conditions. ${ }^{4}$ Chen et al. used phosphoric acid and $\mathrm{H}_{2} \mathrm{O}_{2}$ to research leaching kinetics, and it fits the logarithmic rate kinetics model of cobalt and lithium well. ${ }^{6}$ Pagnanelli et al. utilized sulfuric acid and glucose to extract $96 \%$ of cobalt and $86 \%$ of lithium from spent LIBs. ${ }^{8}$ $\mathrm{Ku}$ et al. treated the waste cathode active materials, which are composites of $\mathrm{LiCo}_{x} \mathrm{Mn}_{y} \mathrm{Ni}_{z} \mathrm{O}_{2}, \mathrm{LiMn}_{2} \mathrm{O}_{4}, \mathrm{Al}_{2} \mathrm{O}_{3}$ and C, with ammonia, ammonium sulfite and ammonium carbonate. ${ }^{10} \mathrm{Li}$ et al. used succinic acid as a leaching agent and $\mathrm{H}_{2} \mathrm{O}_{2}$ as a reductant, and the results showed that $100 \%$ of cobalt and $96 \%$ of lithium were recovered under optimized conditions. ${ }^{11}$ Meshram et al. used an acid mixture $\left(\mathrm{H}_{2} \mathrm{SO}_{4}\right.$ and $\left.\mathrm{HNO}_{3}\right)$ with glucose to recover $93.2 \%$ lithium, $90.52 \%$ cobalt, $82.8 \%$ nickel, and $77.7 \%$ manganese. ${ }^{13}$ Santana et al. used cobalt and lithium recovered from spent LIBs to form a sol-gel material, which can be used as a promising candidate for heterogeneous catalysis. ${ }^{14}$ It is clear from the above discussion that organic acids, which 
Table 1 A brief summary of different leaching systems in the last five years

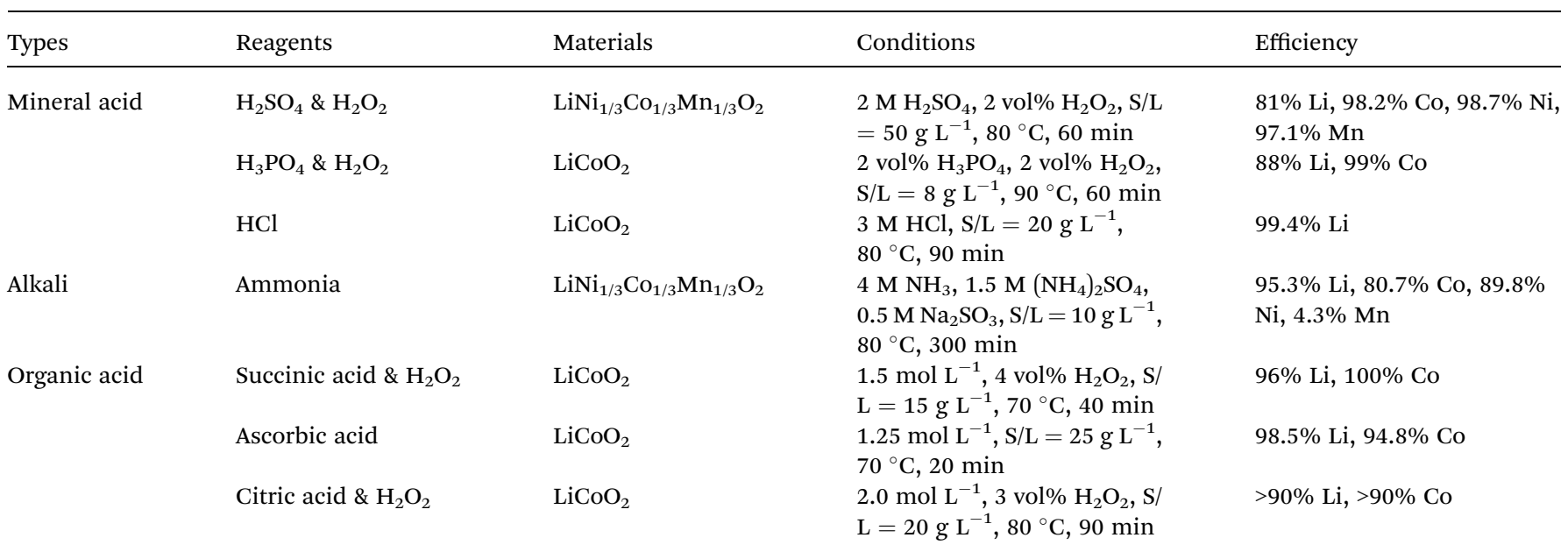

may effectively alleviate environment pollution during leaching, have similar performance as mineral acids.

Although many relevant literatures have been reported for leaching metals under various conditions, the kinetics of the leaching process are less studied, and the mechanism of the leaching process is unclear. ${ }^{15-17}$ Meshram et al. reported that the leaching kinetics of lithium and cobalt follow a logarithmic rate law and chemical control mechanism. ${ }^{16}$ Golmohammadzadeh et al. studied the kinetics of cobalt using different organic acids (acetic acid, oxalic acid, DL-malic acid and citric acid), and the results showed that the kinetics of cobalt leaching is governed by surface layer diffusion of the leachant. ${ }^{17}$

Hence, in our study, formic acid $(\mathrm{HCOOH})$ was selected as the leaching liquid to treat spent LIBs for its low cost (when compared with ascorbic acid, citric acid) and non-polluting and efficient leaching properties. The effects of reaction time, temperature, solid-liquid ratio, $\mathrm{H}_{2} \mathrm{O}_{2}$ concentration and $\mathrm{LiCoO}_{2} / \mathrm{HCOOH}$ ratio were studied to optimize the conditions of leaching. The kinetics of $\mathrm{HCOOH}$ leaching of valuable metals from spent LIBs with a reducing agent were particularly stressed, while establishing the model of leaching kinetics by characterizing waste metals and leaching residues using the XRD and SEM/EDX characterization. Meanwhile, lithium fluoride, as a commonly used industrial lithium salt, is an important raw material for the synthesis of other lithium resources, but is very expensive among the lithium salts. In this study, lithium fluoride was finally obtained by the fractional precipitation of the liquor after leaching, and the physicochemical properties of the recycled products were characterized.

\section{Experimental}

\subsection{Materials and reagents}

LIBs used in mobiles phones from different manufacturers were collected from Hubei University. $\mathrm{HCOOH}$ as a leaching reagent and $\mathrm{H}_{2} \mathrm{O}_{2}$ as a reducing reagent were purchased from the Taicang Lushi Reagent Co., Ltd of China. In the pretreatment step, $N$-methyl-2-pyrrolidone (NMP) was used to separate the cathode material from the aluminum foil. ${ }^{\mathbf{1 8}}$ All the solutions were prepared in distilled water, and all the chemical reagents were of analytical grade.

\subsection{Selective leaching of spent cathode material}

The whole pretreatment and leaching process of spent cathode material with $\mathrm{HCOOH}$ is shown in Fig. 1. First, all spent LIBs were discharged before being dismantled to avoid short-circuit and self-ignition, and the cathode material was scraped from the $\mathrm{Al}$ foil and ground to less than $0.1 \mathrm{~mm}$ diameter. Then, the powder was placed in a muffle oven at $700{ }^{\circ} \mathrm{C}$ for $2 \mathrm{~h}$, aiming to remove the carbon and binder polyvinylidene fluoride (PVDF) in the cathode material. Finally, the leaching experiments were performed in a $500 \mathrm{~mL}$ three-necked round-bottom flask installed with a reflux condenser to prevent loss by evaporation. A heating bath with a magnetic stirrer was used to ensure optimized kinetics conditions and temperature control. After reacting for a preset period, the mixture was filtered immediately. The effects of several factors including the temperature, solid-to-liquid ratio, and reductant concentration were investigated.

\subsection{Fractional precipitation of $\mathrm{Li}$ and $\mathrm{Co}$}

After leaching, the leachate and sodium hydroxide solution (2 M) were simultaneously pumped into the reactor with a speed of $2 \mathrm{~mL} \mathrm{~min}^{-1}$ under the protection of nitrogen at $60{ }^{\circ} \mathrm{C}$ with a stirring speed of $1000 \mathrm{rpm}$. The $\mathrm{pH}$ was first adjusted and maintained at 11 for $24 \mathrm{~h}$ to obtain the cobalt hydroxide precipitate (precipitate I). Then, the raffinate was further adjusted to a neutral $\mathrm{pH}$ with formic acid, and a stoichiometric amount of saturated $\mathrm{NaF}$ was subsequently added to the raffinate at $60{ }^{\circ} \mathrm{C}$ with a speed of $1 \mathrm{~mL} \mathrm{~min}^{-1}$. The precipitated $\mathrm{LiF}$ (precipitate II) was washed with distilled water and dried in a vacuum oven for $12 \mathrm{~h}$.

\subsection{Material characterization}

To determine the lithium and cobalt concentration after grinding, calcination and leaching, the spent material was dissolved using nitric acid and tested using an Atomic 


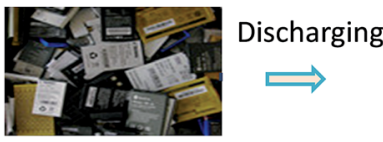

Spent LIBs
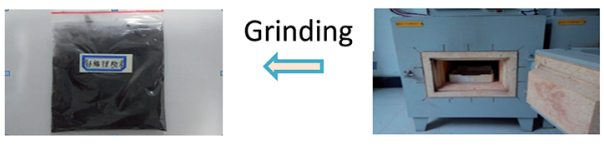

$\mathrm{LiCoO}_{2}$

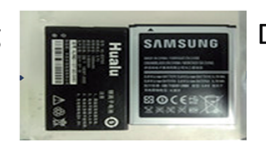

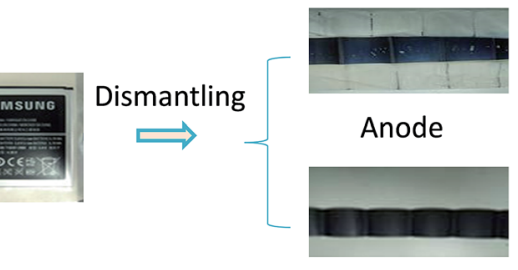

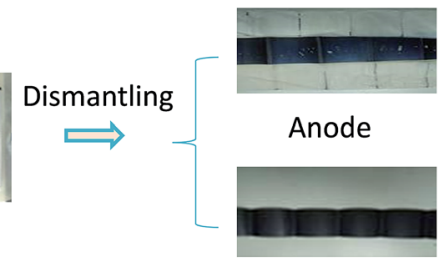

Cathode

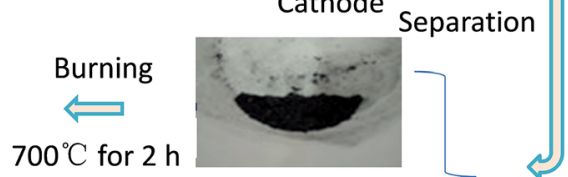

Cathode materials

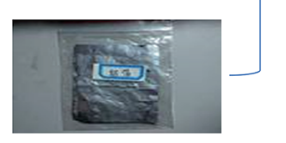

Al foils
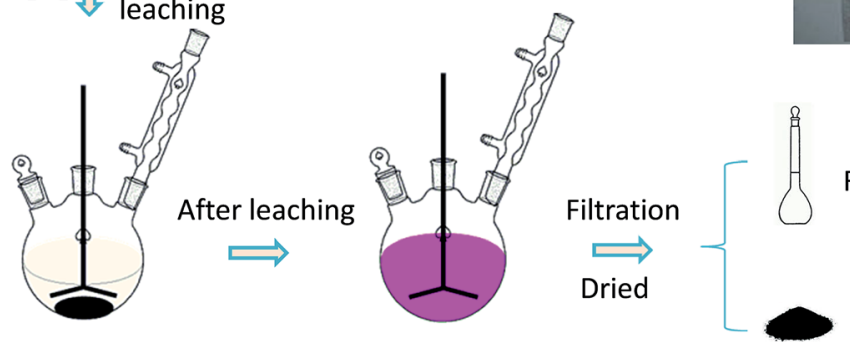

Filtrate for AAS analysis

Residue for XRD and

SEM analysis

Absorption Spectrophotometer (AAS, AAnalyst 400, PerkinElmer). The phase components and morphology of the spent cathode active material were characterized using X-ray diffraction (XRD, D8 ADVANCE, BRUKER) with $\mathrm{Cu} \mathrm{K} \alpha$ radiation $(1.54 \AA)$ at a voltage of $40 \mathrm{kV}, 300 \mathrm{~mA}$ and scanning electron microscopy (SEM, S4700, TOSHIBA), respectively, before and after leaching. The thermo-stability of the spent cathode material was tested using a thermal gravimetric analyzer (TGA, TGA2, METTLER TOLEDO) before leaching.

\section{Results and discussion}

\subsection{Mechanism of leaching}

$\mathrm{HCOOH}$ is a medium strong acid among organic acids, and its ionization equation in $25{ }^{\circ} \mathrm{C}$ water can be explained as:

$$
\mathrm{HCOOH}=\mathrm{H}^{+}+\mathrm{COOH}^{-}
$$

Its $K_{\mathrm{a}}$ is $1.8 \times 10^{-4}$, which indicates that it can provide enough $\mathrm{H}^{+}$ions for the leaching reaction. Moreover the carbon atom of $\mathrm{HCOOH}$ molecule with the assistance of $\mathrm{H}_{2} \mathrm{O}_{2}$ can act as a reductant in aqueous solution. ${ }^{19,20}$ First, with the help of $\mathrm{H}_{2} \mathrm{O}_{2}$, the cobalt in the cathode materials is reduced from high valence $\mathrm{Co}\left(\mathrm{LiCoO}_{2}, \mathrm{Co}_{3} \mathrm{O}_{4}\right.$ and trace $\left.\mathrm{Co}_{2} \mathrm{O}_{3}\right)$ to $\mathrm{Co}^{2+}$, which makes it more stable and dissolvable in $\mathrm{HCOOH}$ aqueous solution. ${ }^{21,22}$ Then, $\mathrm{Li}^{+}$and $\mathrm{Co}^{2+}$ react with $\mathrm{COOH}^{+}$during the whole leaching process. After calcination, the product of $\mathrm{CoO}$ may be generated in the powder, whereas $\mathrm{CoO}$ can be directly leached out. Fig. 2 shows the main leaching reaction of spent materials and $\mathrm{HCOOH}$ and theoretically, $\mathrm{LiCOOH}$ and $\mathrm{Co}(\mathrm{COOH})_{2}$ are the two main leaching products as shown in the following equation:

$$
\begin{gathered}
6 \mathrm{HCOOH}+2 \mathrm{LiCoO}_{2}+\mathrm{H}_{2} \mathrm{O}_{2}= \\
2 \mathrm{Co}(\mathrm{COOH})_{2}+2 \mathrm{LiCOOH}+4 \mathrm{H}_{2} \mathrm{O}+2 \mathrm{O}_{2} \\
4 \mathrm{HCOOH}+2 \mathrm{CoO}=2 \mathrm{Co}(\mathrm{COOH})_{2}+2 \mathrm{H}_{2} \mathrm{O}
\end{gathered}
$$

\subsection{Characterization of $\mathrm{LiCoO}_{2}$ in spent LIBs}

The spent $\mathrm{LiCoO}_{2}$ powder was heated from $30{ }^{\circ} \mathrm{C}$ to $1000{ }^{\circ} \mathrm{C}$ using TGA in an air atmosphere at a heating rate of $10^{\circ} \mathrm{C} \mathrm{min}^{-1}$. In Fig. 3a, the TGA results indicate that a weight loss of $1.02 \mathrm{wt} \%$ was found from $30{ }^{\circ} \mathrm{C}$ to $283{ }^{\circ} \mathrm{C}$ due to the loss of bound water. From $283{ }^{\circ} \mathrm{C}$ to $700{ }^{\circ} \mathrm{C}$, there was a weight loss of $5.96 \mathrm{wt} \%$, possibly resulting from the burning of the powdered carbon and the decomposition of PVDF. When the temperature was between $820^{\circ} \mathrm{C}$ and $1000^{\circ} \mathrm{C}$ in the TG curve, a weight loss of $2.05 \mathrm{wt} \%$ illustrated the phase change of $\mathrm{LiCoO}_{2}$ and the decomposition of $\mathrm{Co}_{3} \mathrm{O}_{4}$ to $\mathrm{CoO}$.

The spent cathodic materials after calcination and the black residues after $\mathrm{HCOOH}$ leaching were analyzed. From the XRD patterns in Fig. 3b, it is clear that the residues had a small amount of $\mathrm{LiCoO}_{2}$ and insoluble $\mathrm{Co}_{3} \mathrm{O}_{4}$ as compared to the spent cathodic materials. This could be due to large amounts of $\mathrm{LiCoO}_{2}$ of the spent cathodic materials reacting with $\mathrm{HCOOH}$ and $\mathrm{Co}_{3} \mathrm{O}_{4}$ being partially leached by $\mathrm{HCOOH}$. The carbon peaks were not detected as can be concluded from Fig. 3b, indicating that a large amount of carbon was burnt off in the calcination process.

The SEM images of the spent cathode active materials after calcination and the residues after $\mathrm{HCOOH}$ leaching are shown in Fig. 4, which presents the spent cathode materials, mostly 


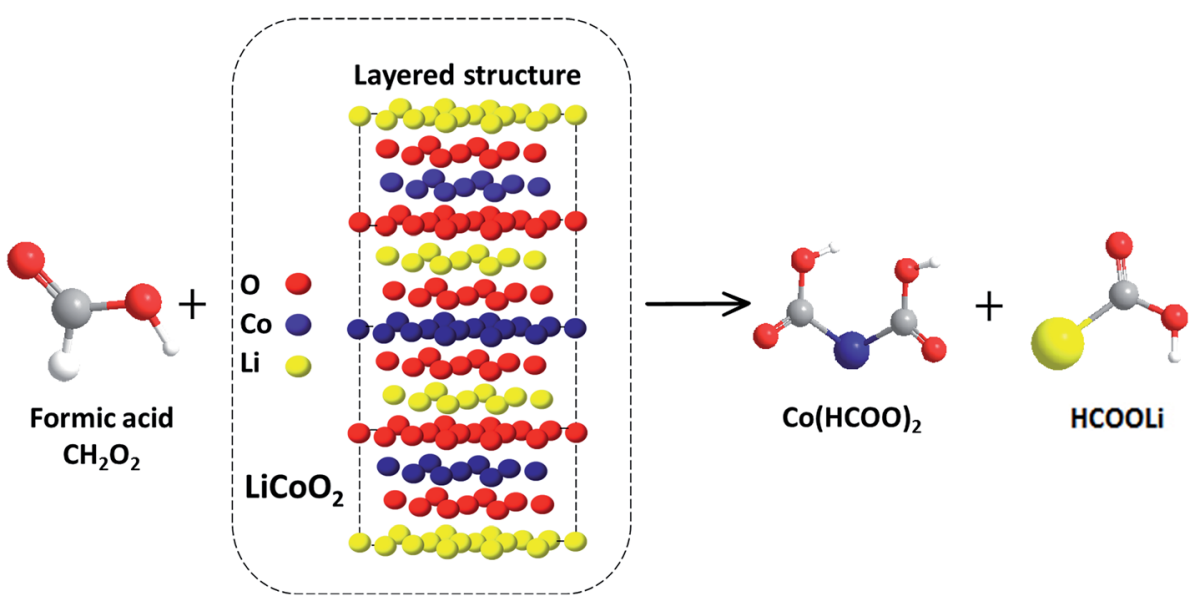

Fig. 2 Leaching mechanism and main products of spent $\mathrm{LiCOO}_{2}$ with $\mathrm{HCOOH}$.

(a)

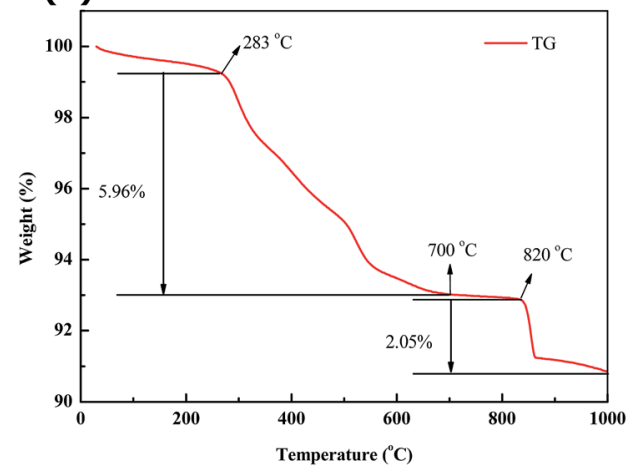

(b)

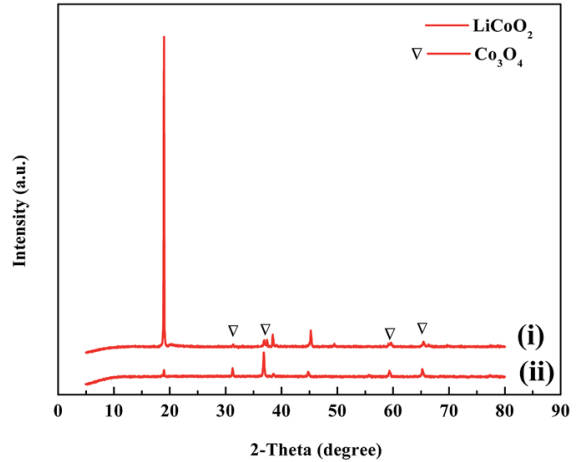

Fig. 3 (a) TG curve for spent cathode materials heated from $30{ }^{\circ} \mathrm{C}$ to $1000^{\circ} \mathrm{C}$ in an air atmosphere with a heating rate of $10{ }^{\circ} \mathrm{C}$ min ${ }^{-1}$; (b) $\mathrm{XRD}$ patterns of (i) spent cathode materials after calcination and (ii) black residues after leaching.

$\mathrm{LiCoO}_{2}$, whose particle diameters are in the range of $5-11 \mu \mathrm{m}$. Moreover, the $\mathrm{LiCoO}_{2}$ particles are irregular and agglomerated because of the repeated usage of LIBs. The leaching residues show a small particle size of about 3-6 $\mu \mathrm{m}$ in Fig. $4 \mathrm{~b}$. The smaller particles are caused because the larger agglomerate particles are broken up in the $\mathrm{HCOOH}$ leaching stirring reaction. From EDS spectroscopy, it is determined that most of the $\mathrm{Co}$ and $\mathrm{O}$ elements can be found in the leaching residues from which we inferred that the residues had a some amount of $\mathrm{Co}_{3} \mathrm{O}_{4}$ and traces of CoO. A small amount of $\mathrm{F}$ and $\mathrm{C}$ elements in the EDS image indicates that plenty of carbon and binder (PVDF) was burnt off during the calcination process.

\subsection{Leaching of $\mathrm{LiCoO}_{2}$ with $\mathrm{HCOOH}$}

The $\mathrm{LiCoO}_{2} / \mathrm{HCOOH}$ ratio plays a vital role in improving the leaching efficiency of cobalt and lithium from spent cathode materials. The $\mathrm{LiCoO}_{2} / \mathrm{HCOOH}$ ratio was varied from $1: 3$ to $1: 10$ at a reaction temperature of $60{ }^{\circ} \mathrm{C}$, reaction time of $20 \mathrm{~min}$, solid-to-liquid $(\mathrm{S} / \mathrm{L})$ ratio of $20 \mathrm{~g} \mathrm{~L}^{-1}$, and $\mathrm{H}_{2} \mathrm{O}_{2}$ concentration of $6 \mathrm{vol} \%$. Fig. 5a shows that when the dosage of $\mathrm{HCOOH}$ was increased, the leaching efficiency of cobalt and lithium, especially the cobalt, improved. Initially the leaching efficiency was about $65 \%$ for cobalt and $88 \%$ for lithium with a $\mathrm{LiCoO}_{2} / \mathrm{HCOOH}$ ratio at $1: 3$ and then, it increased to $81 \%$ for cobalt and $94 \%$ for lithium at $1: 10$ mole ratio. Although the highest leaching efficiency of $81 \%$ for cobalt and $94 \%$ for lithium was obtained at $1: 10$ mole ratio, increasing $\mathrm{HCOOH}$ had little effect on the improvement of the leaching efficiency. These phenomena can be interpreted as follows: when $\mathrm{HCOOH}$ was increased, sufficient ionized $\mathrm{H}^{+}$species were generated to react with $\mathrm{LiCoO}_{2}$ powder in the solid/liquid interphase, and when the interfacial $\mathrm{H}^{+}$concentration was reduced, the additional ionized $\mathrm{H}^{+}$species could diffuse outward. ${ }^{23-25}$ Fig. 2 shows that the theoretical $\mathrm{LiCoO}_{2} / \mathrm{HCOOH}$ reactive ratio was $1: 3$. However, the virtual optimal $\mathrm{LiCoO}_{2} / \mathrm{HCOOH}$ reactive ratio was $1: 10$, resulting from incomplete ionization and gasification loss of $\mathrm{HCOOH}$.

To investigate the effect of $\mathrm{S} / \mathrm{L}$, the experiment was performed at $\mathrm{S} / \mathrm{L}$ ratios from 10 to $30 \mathrm{~g} \mathrm{~L}^{-1}$ with the following conditions: $\mathrm{LiCoO}_{2} / \mathrm{HCOOH}$ ratio of $1: 10$, leaching temperature of $60{ }^{\circ} \mathrm{C}$, leaching time of $20 \mathrm{~min}$, and $\mathrm{H}_{2} \mathrm{O}_{2}$ concentration of 6 vol\%. From Fig. 5b, it can be observed that the leaching efficiency of cobalt and lithium from the spent $\mathrm{LiCoO}_{2}$ powder appeared to first increase and then decrease with increasing $\mathrm{S} / \mathrm{L}$ 

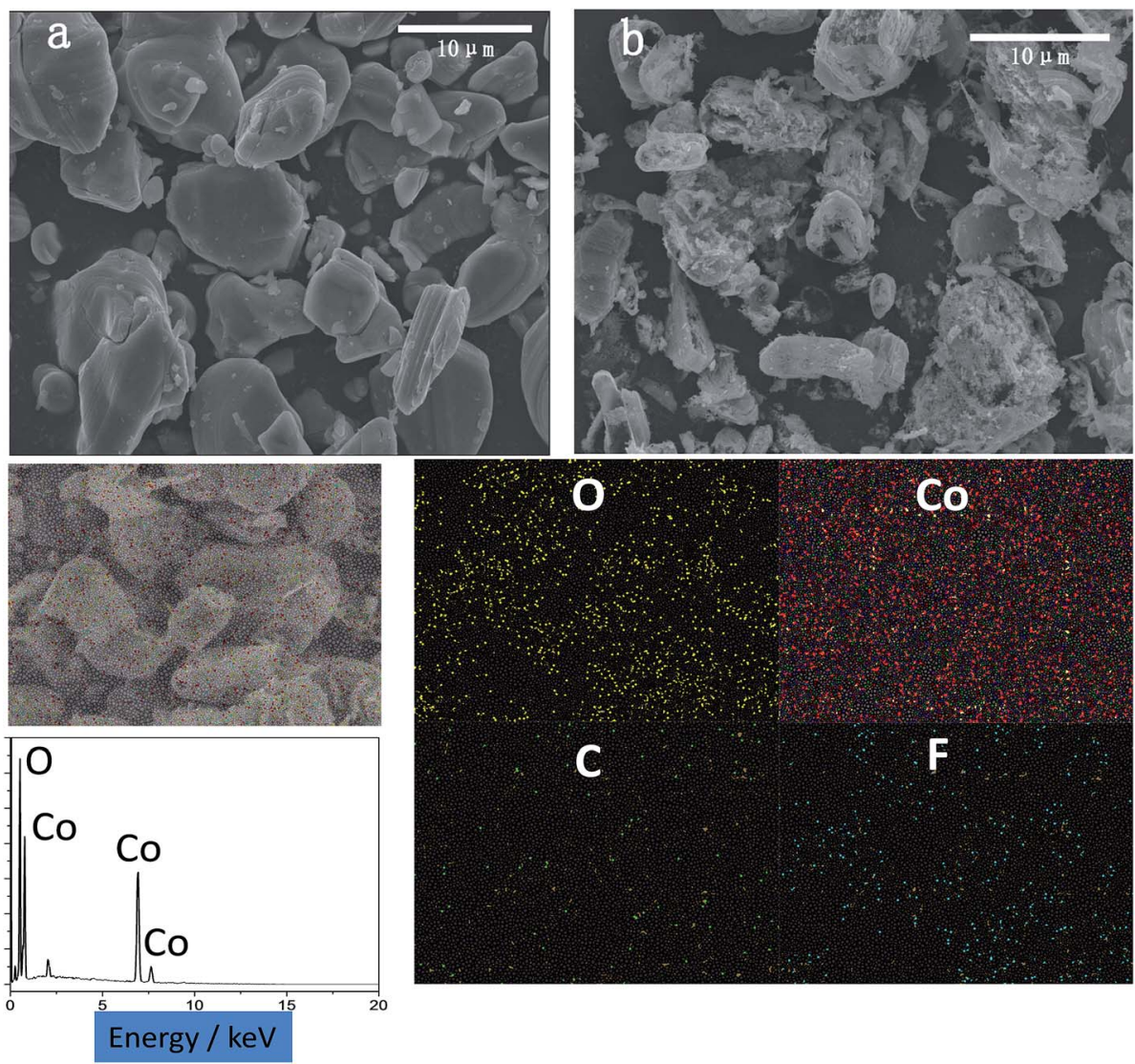

Fig. 4 SEM micrographs of (a) spent cathode materials after calcination and (b) black residues after leaching; EDS spectroscopy of leaching residues.

ratio. The highest leaching efficiency was $85 \%$ for cobalt and 93\% for lithium; however, the leaching efficiency was significantly decreased to $62 \%$ for cobalt and $86 \%$ for lithium at an S/L ratio of $30 \mathrm{~g} \mathrm{~L}^{-1}$. As shown in Fig. $5 \mathrm{c}$ and d, at a low $\mathrm{S} / \mathrm{L}$ ratio, the leaching solution included abundant water molecules so that $\mathrm{HCOOH}$ had a strong ionized capacity and low concentration. With the S/L ratio increasing, the ionized capacity of $\mathrm{HCOOH}$ became increasingly weak, and the concentration of $\mathrm{HCOOH}$ became increasingly high. At a high $\mathrm{S} / \mathrm{L}$ ratio, some water molecules led to a weak ionized capacity and high concentration of $\mathrm{HCOOH}$. Thus, the leaching efficiency of Co and $\mathrm{Li}$ increased initially and decreased afterwards. The S/L ratio of $20 \mathrm{~g} \mathrm{~L}^{-1}$ was chosen to be optimal for leaching valuable metals.

The effect of the leaching temperature on the leaching efficiency of lithium and cobalt was studied under the condition of the $\mathrm{LiCoO}_{2} / \mathrm{HCOOH}$ ratio of $1: 10, \mathrm{H}_{2} \mathrm{O}_{2}$ concentration of $6 \mathrm{vol} \%$, and $\mathrm{S} / \mathrm{L}$ ratio of $20 \mathrm{~g} \mathrm{~L}^{-1}$. With the temperature increasing from 30 to $60^{\circ} \mathrm{C}$, the slopes of the leaching curves for $\mathrm{Li}$ and Co metals both significantly increased (Fig. 6a and b), indicating that the leaching process was an endothermic reaction. However, the leaching behavior of $\mathrm{Li}$ was found to be very different from that of $\mathrm{Co}$, that is, the leaching efficiency of $\mathrm{Li}$ rapidly reached over $90 \%$ within 20 minutes in the early stage of leaching and remained stable afterwards. The leaching efficiency of Co first increased and then decreased with the increase in temperature, especially at high temperatures $\left(60\right.$ to $\left.80{ }^{\circ} \mathrm{C}\right)$, which could be attributed to the decomposition of hydrogen peroxide when the reaction temperature is higher than $60^{\circ} \mathrm{C}$. Therefore, the leaching efficiency was not significantly improved after $60{ }^{\circ} \mathrm{C}$ by further increasing the leaching temperature.

The effect of concentration of $\mathrm{H}_{2} \mathrm{O}_{2}$ as the reducing agent on the leaching efficiency was investigated using a $\mathrm{LiCoO}_{2} / \mathrm{HCOOH}$ ratio of $1: 10, \mathrm{~S} / \mathrm{L}$ ratio of $20 \mathrm{~g} \mathrm{~L}^{-1}$ and temperature of $60^{\circ} \mathrm{C}$ for $20 \mathrm{~min}$. The results, observed in Fig. $6 \mathrm{c}$ and d, indicate that the leaching efficiency of Li was not obviously affected by the concentration of $\mathrm{H}_{2} \mathrm{O}_{2}$ and increased significantly, reaching almost $100 \%$ within $10 \mathrm{~min}$. On the contrary, the leaching efficiency of Co under any $\mathrm{H}_{2} \mathrm{O}_{2}$ concentration increased rapidly within $10 \mathrm{~min}$ and then decreased steadily before reaching a certain low level. It must be pointed out that $\mathrm{Co}^{3+}$ was reduced to $\mathrm{Co}^{2+}$ by $\mathrm{H}_{2} \mathrm{O}_{2}$ to be more easily reactive with $\mathrm{HCOOH}$, that is to say, $\mathrm{H}_{2} \mathrm{O}_{2}$ as a reductant helped dissolve cobalt in the crystals of $\mathrm{LiCoO}_{2}$. Meanwhile, when the concentration and dosage of $\mathrm{H}_{2} \mathrm{O}_{2}$ was increased, the molecules of $\mathrm{H}_{2} \mathrm{O}_{2}$ disintegrated sharply due to the excess $\mathrm{H}_{2} \mathrm{O}_{2}$, according to the following equation and thus, the best concentration of $\mathrm{H}_{2} \mathrm{O}_{2}$ was chosen to be $6 \mathrm{vol} \%$.

$$
\mathrm{H}_{2} \mathrm{O}_{2}(\mathrm{aq})=\mathrm{H}_{2} \mathrm{O}(\mathrm{aq})+\mathrm{O}_{2}(\mathrm{~g})
$$

Therefore, on the basis of the previous experimental results, the global recovery efficiency of Li and Co could reach 

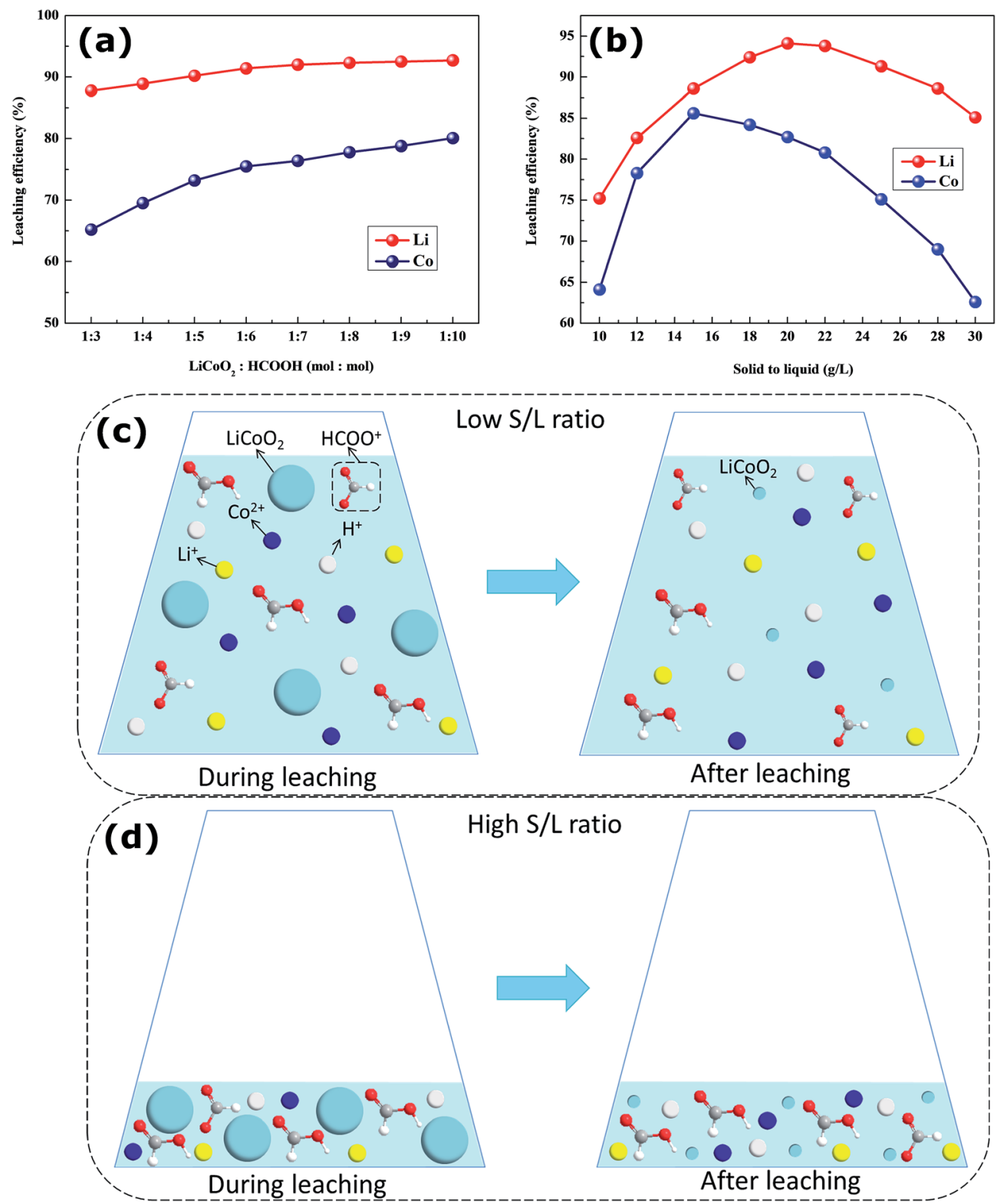

Fig. 5 Effects of (a) $\mathrm{LiCOO}_{2} / \mathrm{HCOOH}$ ratio and $\mathrm{S} / \mathrm{L}$ ratio on the leaching of $\mathrm{Co}$ and $\mathrm{Li}$ from spent $\mathrm{LiCoO} 2$ batteries; (b) possible multiphase leaching reactions of $\mathrm{LiCOO}_{2}$ particles and $\mathrm{HCOOH}$ solutions at (c) low $\mathrm{S} / \mathrm{L}$ ratio and (d) high $\mathrm{S} / \mathrm{L}$ ratio.

99.90\% and $99.96 \%$, respectively, at the following optimal leaching conditions: $\mathrm{LiCoO}_{2} / \mathrm{HCOOH}$ ratio of $1: 10, \mathrm{~S} / \mathrm{L}$ ratio of $20 \mathrm{~g} \mathrm{~L}^{-1}$, and $\mathrm{H}_{2} \mathrm{O}_{2}$ concentration of $6 \mathrm{vol} \%$ at a temperature of $60{ }^{\circ} \mathrm{C}$ for $20 \mathrm{~min}$. Co metal was recovered in the form of cobalt hydroxide precipitate, whereas $\mathrm{Li}$ metal was recycled in the form of LiF.

\subsection{Kinetics of leaching}

To further explore the mechanism of the reaction between the $\mathrm{LiCoO}_{2}$ powder and leachant, the kinetics of leaching were studied in the $\mathrm{HCOOH}$ solution for different leaching temperatures $\left(40-80{ }^{\circ} \mathrm{C}\right.$ ) and times (5-40 $\left.\mathrm{min}\right)$ under the following condition: $\mathrm{LiCoO}_{2} / \mathrm{HCOOH}$ ratio of $1: 10, \mathrm{~S} / \mathrm{L}$ ratio of $20 \mathrm{~g} \mathrm{~L}^{-1}$, and $\mathrm{H}_{2} \mathrm{O}_{2}$ concentration of $6 \mathrm{vol} \%$. From the details of Fig. 7, an approach was adopted to fit the kinetic data satisfactorily using the empirical model based on the surface chemical control, described by eqn (5):

$$
1-3(1-x)^{\frac{2}{3}}+2(1-x)=k_{\mathrm{c}} t
$$

here, $x$ is the fraction of metals leached in time $t$ (minutes) and $k_{\mathrm{c}}$ is the reaction rate constant $\left(\mathrm{min}^{-1}\right)$. The plots of ' $\left(1-3(1-x)^{\frac{2}{3}}+2(1-x)\right)$ vs. $t$ ' at different temperatures showed that the kinetic data fitted well to this kinetic model, which had high correlation coefficients $\left(R^{2}>0.96\right)$ ranging from 0.96 to 0.99 for $\mathrm{Li}$ and 0.97 to 0.99 for Co.

From the Arrhenius eqn (6), the relation between the reaction rate constant mentioned in eqn (5) and the temperature 

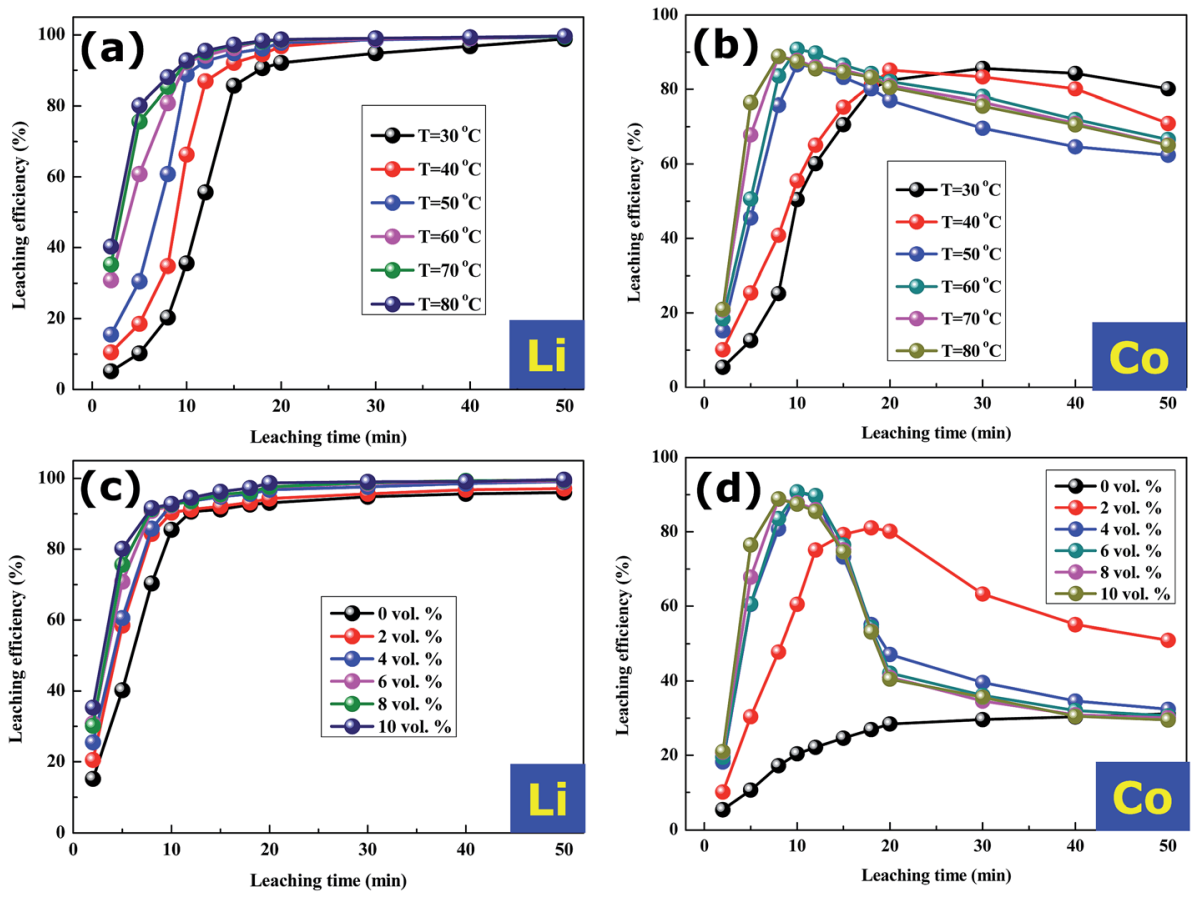

Fig. 6 Effects of $(a, b)$ leaching temperature and $(c, d) \mathrm{LiCoO}_{2} / \mathrm{H}_{2} \mathrm{O}_{2}$ ratio on the leaching of $\mathrm{Li}$ and Co from spent $\mathrm{LiCoO}$ batteries.
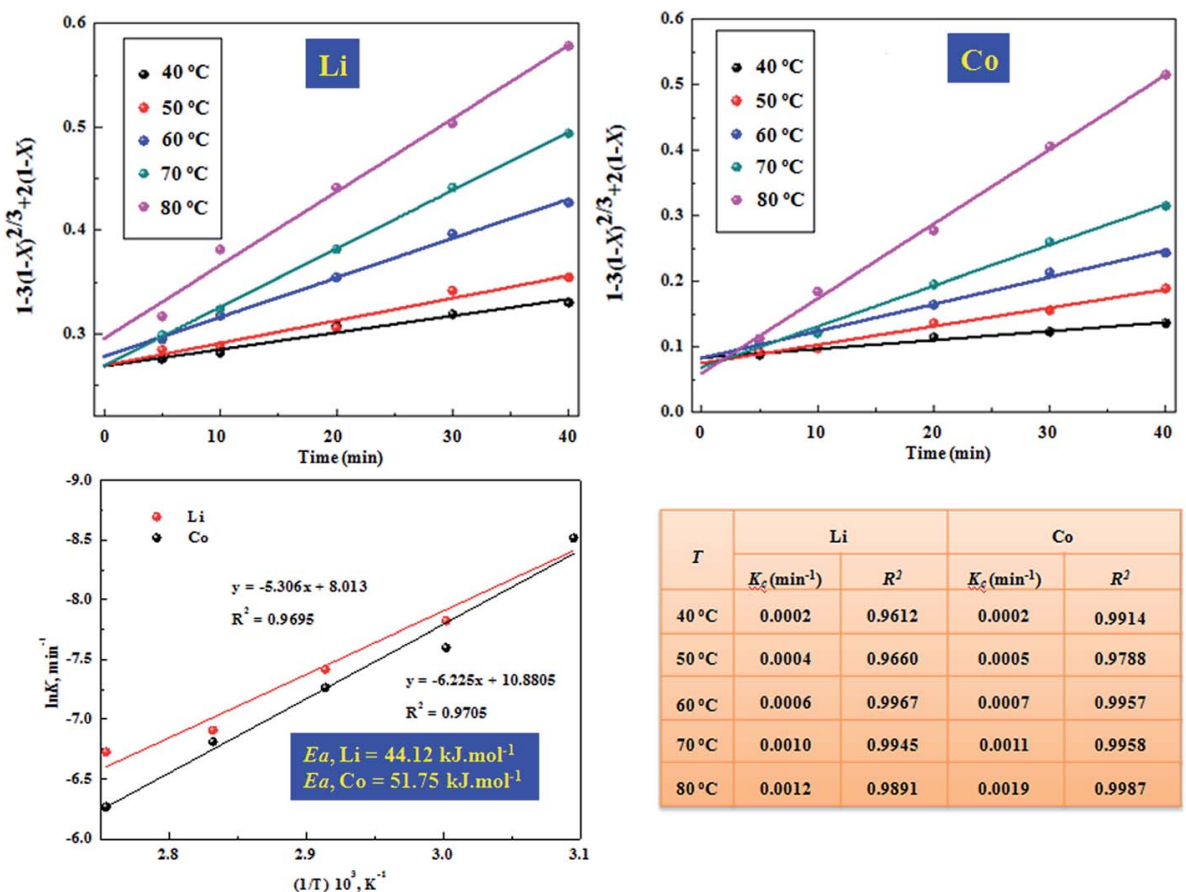

\begin{tabular}{|c|c|c|c|c|}
\hline \multirow{2}{*}{$T$} & \multicolumn{2}{|c|}{$\mathrm{Li}$} & \multicolumn{2}{c|}{$\mathrm{C}_{0}$} \\
\hline & $\boldsymbol{K}_{f}\left(\mathrm{~min}^{-1}\right)$ & $\boldsymbol{R}^{2}$ & $K_{f}\left(\mathrm{~min}^{-1}\right)$ & $R^{2}$ \\
\hline $40^{\circ} \mathrm{C}$ & 0.0002 & 0.9612 & 0.0002 & 0.9914 \\
\hline $50^{\circ} \mathrm{C}$ & 0.0004 & 0.9660 & 0.0005 & 0.9788 \\
\hline $60^{\circ} \mathrm{C}$ & 0.0006 & 0.9967 & 0.0007 & 0.9957 \\
\hline $70^{\circ} \mathrm{C}$ & 0.0010 & 0.9945 & 0.0011 & 0.9958 \\
\hline $80^{\circ} \mathrm{C}$ & 0.0012 & 0.9891 & 0.0019 & 0.9987 \\
\hline
\end{tabular}

Fig. 7 Chemical control model for leaching kinetics of Co and Li at different temperatures; Arrhenius plot for the leaching of Li and Co under the chemical control model.

can be explained, and the activation energy can be calculated by the following equation:

$$
k=A \mathrm{e}^{-E_{\mathrm{a}} / R T}
$$

Here, $k$ is the reaction rate constant, $A$ is the frequency factor, $E_{\mathrm{a}}$ is the apparent activation energy and $R$ is the gas constant
(8.314 $\mathrm{J} \mathrm{K}^{-1} \mathrm{~mol}^{-1}$ ). From further plotting 'In $k v s$. $1 / T$ ', as shown in Fig. 7, the apparent activation energy is calculated to be $44.12 \mathrm{~kJ} \mathrm{~mol}^{-1}$ for $\mathrm{Li}$, and $51.75 \mathrm{~kJ} \mathrm{~mol}^{-1}$ for Co. The values reach the specified activation energies for chemical reaction control $\left(>42 \mathrm{~kJ} \mathrm{~mol}^{-1}\right) .{ }^{22}$ 


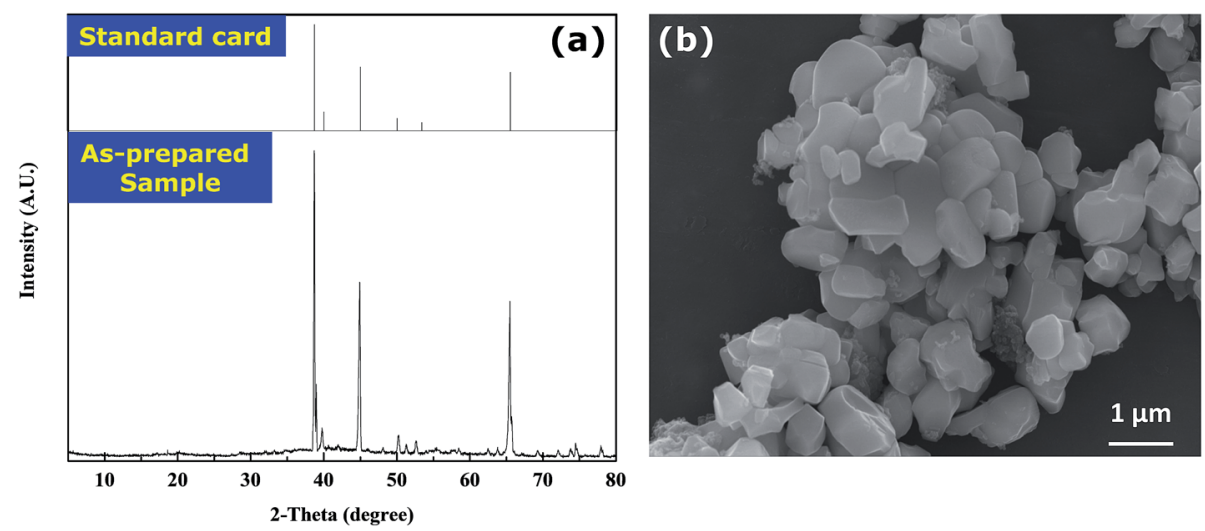

Fig. 8 (a) XRD patterns of the precipitated LiF and standard powder diffraction peaks of LiF; (b) SEM images of the precipitated LiF.

\subsection{Recovery of lithium fluoride}

The leaching solution is first processed according to the aforementioned procedures to precipitate Co metal. Subsequently, lithium fluoride can be obtained by adding saturated $\mathrm{NaF}$ to the remaining leaching solution. The XRD pattern of the obtained lithium fluoride is shown in Fig. 8a, and it agrees well with the standard patterns of peaks. The SEM image of the precipitated $\mathrm{LiF}$ can be also seen in Fig. $8 \mathrm{~b}$, and it can be noticed that the precipitated $\mathrm{LiF}$ is present as massive agglomerates integrated by numerous primary sheets (estimated to be $1.00 \pm 0.50 \mu \mathrm{m})$. Meanwhile, to accurately calculate the purity of lithium fluoride, the precipitated LiF is further dissolved by aqua regia and the mass fraction of metals is measured by AAS. After calculation, the mass fraction of lithium is found to be $99.0 \mathrm{wt} \%$.

\section{Conclusions}

Recycling cobalt and lithium from spent LIBs is considered to be a beneficial and crucial way to prevent environmental pollution and alleviate resource shortage. In this study, we proposed the hydrometallurgical process for recovery of lithium fluoride as the target product. The spent cathode material could be first leached out using formic acid and hydrogen peroxide. To achieve efficient leaching, the molar ratio of formic acid and $\mathrm{LiCoO}_{2}$ at $10: 1$, a leaching temperature of $60{ }^{\circ} \mathrm{C}$, a solid-to-liquid ratio of $20 \mathrm{~g} \mathrm{~L}^{-1}$ and reaction time of $20 \mathrm{~min}$ were used as optimal conditions. With the help of these conditions, more than $99.96 \%$ of Co and $99.90 \%$ of $\mathrm{Li}$ could be recovered from the spent batteries. Meanwhile, by evaluating the leaching kinetics and calculating the apparent activation energies, the leaching process was verified to be controlled by the chemical reaction satisfactorily. After further fractional precipitation, a highly pure (99.0\%) lithium fluoride could be finally obtained.

\section{Conflicts of interest}

There are no conflicts to declare.

\section{Acknowledgements}

The authors gratefully acknowledge financial support from the National Natural Science Foundation of China (No. 21706055). The authors would like to thank the Analytical and Testing Center of Hubei University for providing the facilities to complete the experimental measurements. Technical support from Hubei Nuobang Chemical Company Co. Ltd., is also gratefully acknowledged.

\section{References}

1 P. K. Choubey, K. S. Chung, M. S. Kim, J. C. Lee and R. R. Srivastava, Miner. Eng., 2017, 110, 104-121.

2 G. P. Nayaka, K. V. Pai, J. Manjanna and S. J. Keny, Waste Manage., 2015, 51, 234-238.

3 F. Tesfaye, D. Lindberg and J. Hamuyuni, Miner. Eng., 2017, 111, 209-221.

4 X. P. Chen, Y. B. Chen, T. Zhou, D. P. Liu and H. Hu, Waste Manage., 2015, 38, 349-356.

5 E. G. Pinna, M. C. Ruiz and M. W. Ojeda, Hydrometallurgy, 2017, 167, 66-71.

6 X. P. Chen, H. R. Ma and C. B. Luo, J. Hazard. Mater., 2016, 326, 77-86.

7 Y. Guo, F. Li, H. C. Zhu, G. M. Li and J. W. Huang, Waste Manage., 2015, 51, 227-233.

8 F. Pagnanelli, E. Moscardini, P. Altimari, T. A. Atia and L. Toro, Waste Manage., 2016, 60, 706-715.

9 S. P. Barik, G. Prabaharan and L. Kumar, J. Cleaner Prod., 2017, 147, 37-43.

10 H. Ku, Y. Jung, M. Jo, S. Park and S. Kim, J. Hazard. Mater., 2016, 313, 138-146.

11 L. Li, W. J. Qu, X. X. Zhang, J. Lu and R. J. Chen, J. Power Sources, 2015, 282, 544-551.

12 L. Li, J. Lu, Y. Ren, X. X. Zhang, R. J. Chen and F. Wu, J. Power Sources, 2012, 218, 21-27.

13 P. Meshram, B. D. Pandey and T. R. Mankhand, J. Ind. Eng. Chem., 2016, 43, 117-126.

14 I. L. Santana, T. F. M. Moreira, M. F. F. Lelis and M. B. J. G. Freitas, Mater. Chem. Phys., 2017, 190, 38-44. 
15 X. H. Zheng, W. F. Gao, X. H. Zhang, M. M. He and X. Lin, Waste Manage., 2016, 60, 680-688.

16 P. Meshram, B. D. Pandey and T. R. Mankhand, Chem. Eng. J., 2015, 281, 418-427.

17 R. Golmohammadzadeh, F. Rashchi, E. Vahidi and E. Vahidi, Waste Manage., 2017, 321, 561-578.

18 N. S. Prasad, S. Moulik, S. Bohra, K. Y. Rani and S. Sridhar, Carbohydr. Polym., 2015, 136, 1170-1181.

19 H. H. Wu, Y. Wang, H. Li and L. B. Huang, Atmos. Environ., 2017, 164, 61-70.

20 L. Nowicki, D. Siuta and M. Godala, Thermochim. Acta, 2017, 653, 62-70.
21 S. B. Hammouda, F. P. Zhao, Z. Safaei, V. Srivastava, D. L. Ramasamy, S. Iftekhar and S. Kalliola, Appl. Catal., B, 2017, 215, 60-73.

22 W. F. Gao, X. H. Zhang, X. H. Zheng and X. Lin, Environ. Sci. Technol., 2017, 51, 1662-1669.

23 E. Cha, E. S. Jeong, S. Cha and J. Lee, Anal. Chim. Acta, 2017, 964, 123-133.

24 S. M. Pratik and A. Datta, J. Phys. Chem. B, 2016, 120, 76067613.

25 H. Elmongy, H. Ahmed, A. A. Wahbi, H. Koyi and M. A. Rehim, J. Chromatogr. A, 2015, 1418, 110-118. 